\title{
CHRONIC LIVER DISEASE QUESTIONNAIRE IN DUHOK CITY / KURDISTAN REGION OF IRAQ
}

\author{
GHAZWAN A. MOHAMMED \\ Dept. of Pharmacology, College of Pharmacy, University of Duhok, Kurdistan Region- Iraq.
}

(Received: April 11, 2019; Accepted for Publication: July 8, 2019)

\begin{abstract}
Liver disease is one of the widespread diseases in the world where it increased in Duhok City-Kurdistan Region-Iraq. Hence, a study on this disease was performed to determine the causes of this disease and its frequency. The study is an observational study included the use of Chronic Liver Disease Questionnaire (CLDQ) which is a specific health-related quality of life assessment designed for patients with liver diseases along with a descriptive study at Azadi Teaching Hospital in Duhok including 58 patients. The CLDQ measures the impact on quality of life of chronic liver diseases (CLD), regardless of underlying etiology. Reliability and validity of the questionnaire will be determined through the experts. Information was collected through the use of the constructed questionnaire and the method of personal interview was employed.

Aims: The aims of the current study were to review the previous studies on chronic cases related to liver diseases and observe the CLD in Duhok city/ Kurdistan Region of Iraq.

Results: Among these 58 patients, 24 patients (41.4\%) had CLD which was (12 had liver cirrhosis, 11 had hepatitis B virus and one patient had liver metastasis) and 34 patients $(58.6 \%)$ had acute liver disease. This study observed that the most common cause of liver cirrhosis is chronic hepatitis B, followed by alcohol and cryptogenic liver cirrhosis.

Conclusion: This study evidenced that most individuals didn't care about the importance of vaccination, regimen, follow-up, and treatment of the specific conditions related to a liver disorder that improves the quality of life.
\end{abstract}

\section{INTRODUCTION}

W orldwide, chronic liver disease (CLD) is increasingly the major health burden to society. It is estimated to be the fifth most common cause of death after heart disease, stroke, lung disease and cancer. [1] A bout 500 million individuals have CLD with a viral etiology. ${ }^{[2]}$ In terms of liver disease associated with $\mathrm{HCV}$ infection, chronic hepatitis $\mathrm{C}(\mathrm{CH}-\mathrm{C})$ is considered one of the most common and potentially devastating causes of liver disease worldwide. In fact, the clinical, economic, and patient experience impact of $\mathrm{HCV}$ infection has been estimated to cause tremendous burden on patients, their families, and the society. ${ }^{[3,4]}$ Hepatitis infection, fatty liver disease, cancer as well as liver injury from alcohol, the pain reliever acetaminophen, and some cancer drugs induce common liver diseases. Liver dialysis in which a machine performs the detoxification function of the liver still a relatively new treatment and cannot support a person longer than a few years. Dialysis is normally used as a bridge between liver failure and liver transplant surgery. ${ }^{[5]}$

The liver is particularly vulnerable to toxicity produced by reactive metabolites because it is the major site of xenobiotic metabolism. Most activation reactions are catalyzed by the cytochrome P450 enzymes, and agents that induce these enzymes, such as phenobarbital and 3methylcholanthrene that often increase toxicity. Conversely, inhibitors of cytochrome P450, such as SKF-525A and piperonyl butoxide, frequently decrease toxicity. ${ }^{[6]}$

Mechanisms such as conjugation of the reactive chemical with glutathione are protective mechanisms that exist within the cell for the rapid removal and inactivation 
of many potentially toxic compounds. Because of these interactions, cellular toxicity is a function of the balance between the rate of formation of reactive metabolites and the rate of their removal. The clinical picture of viral hepatitis is very variable, including fatal fulminant acute hepatitis, acute hepatitis with complete recovery, or chronic infection leading to cirrhosis and predisposing to hepatocellular carcinoma. ${ }^{[8]}$

Excessive ethanol consumption causes more than $60 \%$ of chronic liver disease in most Western countries and accounts for $40 \%$ to $50 \%$ of deaths due to cirrhosis. Chronic alcohol consumption has a variety of adverse effects. Of great impact, however, are the three distinctive albeit overlapping forms of alcoholic liver disease: (1) hepatic steatosis (fatty liver), (2) alcoholic hepatitis, and (3) cirrhosis, collectively referred to as alcoholic liver disease. Autoimmune hepatitis describes chronic inflammation in the liver attributed to immune responses against self-antigens in the liver. Patients generally have circulating autoantibodies, and $60 \%$ have other autoimmune diseases in addition. In severe cases, autoimmune hepatitis can lead to acute liver failure, and untreated there is often progression to cirrhosis. There is generally a good response to corticosteroid therapy. ${ }^{[7]}$

Although the occurrence of reactive oxygen species in normal metabolism and the concept of oxidative stress were derived from many studies, it is apparent that oxidative stress can occur in almost any tissue, producing a variety of deleterious effects. To date, a number of liver diseases, including alcoholic liver disease, metal storage diseases, and cholestatic liver disease, have been shown to have an oxidative stress component. Reactive oxygen and reactive nitrogen radicals can be formed in a number of ways and if not detoxified, it can interact with biological macromolecules such as DNA and protein or with lipids. Once lipid peroxidation of unsaturated fatty acids in phospholipids is initiated, it is propagated in such a way as to have a major damaging effect on cellular membranes. ${ }^{[9]}$
Liver cancer is the growth and spread of unhealthy cells in the liver which is leading to acute liver failure. Because the liver is made up of different types of cells, many types of tumors can form in the liver. Some of these are cancer and some are not. [10] The aims of the study are; to observe health-related quality of life assessment designed for patients with chronic cases of liver diseases in Duhok City-Kurdistan Region-Iraq.

\section{METHODOLOGY}

An observational study design was conducted on chronic liver disease at Azadi Teaching Hospital in Dohuk city/ Kurdistan Region of Iraq; the (CLDQ) form was translated from English to Kurdish and Arabic languages by forward method, which consists of five parts including: socio-demographic, review of system, medical history, personal history and regimen to assess the frequency of chronic liver disease occurrence. The setting of the study of (CLDQ) was performed at Azadi Teaching Hospital, the questionnaire form was simply designed based on the need of the relevant data, and then data collection and analysis were done according to Statistical Package for the Social Sciences (SPSS) program which included descriptive statistics, frequencies, and descriptive ratio statistics of the collected data.

\section{RESULTS}

All patients have liver disorder included this study. Table 1 shows the general characteristics in chronic liver disease and control participants. It can be noticed that $65 \%$ of the patients were male and $34 \%$ were female. Regarding the marital status, there were $15.5 \%$ single and $84.5 \%$ were married where $12.1 \%$ of patients work at the government, $19 \%$ as non-government, $5.2 \%$ as private and $63 \%$ of them are workless (retirees);62.1\% of them were non-smoking and $37.9 \%$ were smoker.

Small \% of the patients was alcoholic $3.4 \%$, and many of them were nonalcoholic $96.6 \%$. As far as body mass index of patients $17.2 \%$ were underweight, 48.3 
of them were normal, $24.1 \%$ were overweight and 10.3 of them were obese where high $\%$ of patients didn't have regimen, which is about $70.7 \%$, and the remaining had regimen $29.3 \%$. The vaccinated participants were $27.6 \%$ and most of them were non-vaccinated $72.4 \%$. Also, Table 1 show that all patients that had been studied had liver function test and all were with abnormal liver function, whereas $55.2 \%$ of the patients had jaundice and $48.8 \%$ were non jaundice.

Regarding the patient's symptoms $55.2 \%$ of the patients had fever and 44.85 did not have fever; $44.8 \%$ of them had abdominal pain and 55.25 didn't have abdominal pain; $51.7 \%$ of them showed fatigue and $48.3 \%$ were not showing fatigue. On the other hand, many of them were lost their weight which is $41.4 \%$ and the remaining $58.6 \%$ were normal and $20.7 \%$ had diarrhea and $79.3 \%$ didn't have diarrhea. Moreover, $13.8 \%$ of the patients had constipation and $86.2 \%$ didn't have constipation; $20.7 \%$ of the patients had itching and 79.3\% didn't have itching. Patients with mouth dryness were $53.4 \%$ and $46.6 \%$ didn't have dry mouth and $39.7 \%$ had headache and 60.35 didn't have headache.

Table (1): General characteristics in chronic liver disease and control of 58 participants

\begin{tabular}{|c|c|c|c|}
\hline \multicolumn{2}{|c|}{ Characteristics } & \multirow{2}{*}{$\begin{array}{c}\text { Frequency } \\
38 \\
\end{array}$} & \multirow{2}{*}{$\begin{array}{l}\% \\
65.5 \\
\end{array}$} \\
\hline Gender & Males & & \\
\hline & Females & 20 & 34.5 \\
\hline \multirow[t]{2}{*}{ Marital status } & Single & 9 & 15.5 \\
\hline & Married & 49 & 84.5 \\
\hline \multirow[t]{4}{*}{ Occupation } & Government & 7 & 12.1 \\
\hline & Non-Government & 11 & 19.0 \\
\hline & Private & 3 & 5.2 \\
\hline & Workless & 37 & 63.8 \\
\hline \multirow[t]{2}{*}{ Smoking habits } & Non smoking & 36 & 62.1 \\
\hline & Smoking & 22 & 37.9 \\
\hline \multirow[t]{2}{*}{ Alcohol status } & Non alcoholic & 56 & 96.6 \\
\hline & Alcoholic & 2 & 3.4 \\
\hline \multirow[t]{4}{*}{$\mathrm{BMI}$} & Underweight & 10 & 17.2 \\
\hline & Normal & 28 & 48.5 \\
\hline & Overweight & 14 & 24.7 \\
\hline & Obese & 6 & 10.3 \\
\hline \multirow[t]{2}{*}{ Regimen status } & No & 41 & 70.7 \\
\hline & Yes & 17 & 29.3 \\
\hline \multirow[t]{2}{*}{ Vaccine } & No & 42 & 72.4 \\
\hline & Yes & 16 & 27.6 \\
\hline Liver function test & Yes & 58 & 100.0 \\
\hline \multirow[t]{2}{*}{ Jaundice } & Non jaundice & 26 & 44.8 \\
\hline & Jaundice & 32 & 55.2 \\
\hline \multirow[t]{2}{*}{ Fever } & Non fever & 26 & 44.8 \\
\hline & Fever & 32 & 55.2 \\
\hline \multirow[t]{2}{*}{ Abdominal pain } & No & 32 & 55.2 \\
\hline & Yes & 26 & 44.8 \\
\hline \multirow[t]{2}{*}{ Fatigue } & No & 28 & 48.3 \\
\hline & Yes & 30 & 51.7 \\
\hline \multirow[t]{2}{*}{ Weight loss } & No & 34 & 58.6 \\
\hline & Yes & 24 & 41.4 \\
\hline \multirow[t]{2}{*}{ Diarrhea } & Non & 46 & 79.3 \\
\hline & Yes & 12 & 20.7 \\
\hline
\end{tabular}




\begin{tabular}{cccc}
\hline Constipation & No & 50 & 86.2 \\
\cline { 2 - 4 } & Yes & 8 & 13.8 \\
\hline \multirow{2}{*}{ Itching } & No & 46 & 79.3 \\
\cline { 2 - 4 } & Yes & 12 & 20.7 \\
\cline { 2 - 4 } Mouth dryness & No & 27 & 46.6 \\
\cline { 2 - 4 } & Yes & 31 & 53.4 \\
\hline Headache & No & 35 & 60.3 \\
\hline & Yes & 23 & 39.7 \\
\hline
\end{tabular}

Table 2 illustrates the frequencies and \% of patient's medical history. Among the 58 samples that were taken, 16 of them had no medical history, 6 of them had only HBV without any other diseases, 5 of them had only liver cirrhosis without any other diseases, 2 of them had hepatomegaly, 2 of them had only diabetes mellitus without any other diseases, 2 of them had only heart disease without any other diseases, 1 of them had only kidney diseases without any other diseases, 2 of them had only asthma without any other diseases, 1 of them had only BPH without any other diseases, 1 of them had liver metastasis, 1 of them had Liver cirrhosis, heart disease, kidney disease, and COPD, 1 of them had tuberculosis and stroke, 3 of them had heart disease and diabetes. One of them had hepatitis B and heart disease, 1of them had HBV and BPH, 1 of them had liver cirrhosis, heart disease and diabetes mellitus, 1 of them had HBV, ulcer, and diabetes mellitus, 1 of them had liver cirrhosis and heart disease, 1 of them had heart disease and asthma, 2 of them had heart disease and diabetes mellitus, 1 of them had HBV and diabetes, 1 of them had heart disease and kidney disease, 1 of them had heart disease and COPD, 1 of them had liver cirrhosis, heart disease and stroke, 1 of them had liver cirrhosis and asthma, 1 of them had liver cirrhosis and heart disease, 1 of them had HBV, liver cirrhosis and asthma.

Table (2): Patient's medical history

\begin{tabular}{ccc}
\hline Medical history & Frequency & \% \\
\hline No medical history & 16 & 27.5 \\
\hline HBV & 6 & 10.3 \\
\hline Liver cirrhosis & 5 & 8.6 \\
\hline Hepatomegaly & 2 & 3.4 \\
\hline Diabetes mellitus & 2 & 3.4 \\
\hline Heart diseases & 2 & 3.4 \\
\hline Kidney diseases & 1 & 1.7 \\
\hline Asthma & 2 & 3.4 \\
\hline BPH & 1 & 1.7 \\
\hline Liver cirrhosis, Heart, kidney disease and COPD & 1 & 1.7 \\
\hline & & 1.7 \\
\hline & & 1 \\
\hline
\end{tabular}




\begin{tabular}{|c|c|c|}
\hline Tuberculosis and stroke & 1 & 1.7 \\
\hline Heart disease and diabetes & 3 & 5.2 \\
\hline HBV and heart disease & 1 & 1.7 \\
\hline $\mathrm{HBV}$ and $\mathrm{BPH}$ & 1 & 1.7 \\
\hline Liver cirrhosis, heart disease and diabetes & 1 & 1.7 \\
\hline HBV, Ulcer and diabetes & 1 & 1.7 \\
\hline Liver cirrhosis and heart disease & 1 & 1.7 \\
\hline Heart disease and asthma & 1 & 1.7 \\
\hline Heart disease and diabetes & 2 & 3.4 \\
\hline HBV and diabetes & 1 & 1.7 \\
\hline Heart and kidney diseases & 1 & 1.7 \\
\hline Heart disease and COPD & 1 & 1.7 \\
\hline Liver cirrhosis, heart disease and strok & 1 & 1.7 \\
\hline Liver cirrhosis and asthma & 1 & 1.7 \\
\hline Liver cirrhosis and heart diseases & 1 & 1.7 \\
\hline HBV, Liver cirrhosis and asthma & 1 & 1.7 \\
\hline Total & 58 & 100.0 \\
\hline
\end{tabular}

Table 3 presents the frequencies and \% of patient's surgical history. Most of patients that were studied (about 34 of samples) had no surgical history; one of them had kidney transplantation, 3 of them had appendectomy, 1 had cancer surgery, 2 had eye surgery, 2 had kidney surgery, 3 had gallectomy, 2 had gastric surgery, 2 had hernia surgery, 1 had hemorrhoid surgery, 1 had spleen surgery, 1 had prostatic surgery, 1 had both kidney surgery and hernia, 2 had both eye surgery and gallectomy, 1 had both cancer and kidney surgery and 1 had both gallectomy and spleen surgery.

Table (3): Patient's surgical history

\begin{tabular}{ccc}
\hline Surgical history & Frequency & $\%$ \\
\hline No surgical history & 34 & 58.6 \\
\hline Kidney transplantation & 1 & 1.7 \\
\hline Appendectomy & 3 & 5.2 \\
\hline Cancer surgery & 1 & 1.7 \\
\hline
\end{tabular}




\begin{tabular}{ccc}
\hline Eye surgery & 2 & 3.4 \\
\hline Kidney surgery & 2 & 3.4 \\
\hline Gallectomy & 3 & 5.2 \\
\hline Gastric surgery & 2 & 3.4 \\
\hline Hernia & 2 & 3.4 \\
\hline Hemorrhoid & 1 & 1.7 \\
\hline Spleen surgery & 1 & 1.7 \\
\hline Prostate surgery & 1 & 1.7 \\
\hline Kidney surgery and hernia & 1 & 1.7 \\
\hline Eye surgery and gallectomy & 2 & 3.4 \\
\hline Cancer and kidney surgery & 1 & 1.7 \\
\hline Gallectomy and spleen surgery & 58 & 1.7 \\
\hline Total & 100.0 \\
\hline
\end{tabular}

\section{DISCUSSION}

This study was done by the use of (CLDQ) which is a specific health-related quality of life assessment designed for patients with liver diseases. A translated and adapted version of the Chronic Liver Disease Questionnaire (CLDQ) has been found to be valid and reliable for assessing health-related quality of life in a multiracial Asian population with chronic liver disease. One of the limitations to the study was its relatively small sample size, particularly of patients with decompensated cirrhosis. We believe this was one of the main reasons the overall CLDQ domain scores were higher than in other studies. [11] Chronic liver disease questionnaire was administered on (58) patients, who were admitted to Azadi Teaching Hospital in Duhok city / Kurdistan Region of Iraq. According to the obtained results, among these 58 patients, 24 patients had chronic liver disease (12 of them had liver cirrhosis, 11 of them had hepatitis B virus and 1 patients had liver metastasis). The diagnosis of chronic hepatitis B virus (HBV) infection was based on the presence of hepatitis B surface antigen for more than six months and elevated serum alanine amino-transferase levels with or without HBV DNA, detected by real-time polymerase chain reactions (PCR). ${ }^{[12] ~ A l s o, ~ t h e ~ f r e q u e n c y ~ o f ~ c h r o n i c ~}$ liver disease in Duhok city in male patients is higher than in females despite females have a higher frequency of concurrent immunological disorders such as Sicca Syndrome at presentation than males. ${ }^{[13]}$ In liver cirrhosis, 8 of them are male and only 4 of them are female. In hepatitis B virus, 8 of them are male and 3 of them are female and 1 sample is liver metastasis which is female. The liver disease has many causes, according to our study in duhok city the causes of the liver disease may include the diet patron; 41 samples didn't follow a regimen program where 20 patients were overweight and obese which consequently had an adverse effects on the liver. Also, it can be noticed that 37 patients are workless which may cause obesity and affect the liver. The obese subjects with a low 
socioeconomic status differ significantly from those with a high socioeconomic status in terms of self-perceived health, quality of life, and the intensity of physical activities. [14] Twenty two of patients were smoker and 2 patients were alcoholic, were of no doubt aggregate liver attack. Many of these patients had comorbid diseases such as diabetes, heart disease, gastric disease, gall bladder which collectively may increase the risk of the liver disease. Most of the patients didn't take vaccine which in turn may be the cause of hepatitis infection. Due to comorbid diseases, the patients took many drugs (such as antihypertensive, antidiabetics, paracetamol for headache and many others drugs) which may have a negative effect on liver function. The DrugInduced Liver Injury Network (DILIN), founded in the united state by the National Institute of Diabetes and Digestive and Kidney Diseases (NIDDK), is probably the most trustworthy DILI registries in the world. ${ }^{[15]}$ The current study showed that the majority of signs and symptoms of liver disease are (32 patients with jaundice, 32 patients with fever, 30 patients with fatigue, 31 patients with mouth dryness, 26 patients with abdominal pain, 24 patients with weight loss and 23 patients with headache). All samples had elevated liver functions panel (GOT, GPT, Bilirubin, and alkaline phosphate). Elevation of these panels don't indicate only liver disease but these panels my increase in other diseases like heart disease, surgery, bone disease and others. Alkaline phosphatase may also be fractionated to better delineate bone, intestinal or hepatic origin of an elevated alkaline phosphatase. In children and the elderly, alkaline phosphatase levels increase, especially females over 50 years of age, in part due to bone turnover. Bilirubin comes from the breakdown of senescent red blood cells and predominantly circulates in its unconjugated form tightly bound to albumin. ${ }^{[16]}$

\section{CONCLUSIONS}

According to the findings of the study, the followings could be concluded:

1- Most of the patients (about 41 samples) didn't take regimen which might be considered as one of the causes of liver diseases and increase the risk of negative liver function.

2- Only 16 patients took vaccine, which perhaps expose patients to hepatitis which in turn affect liver function.

3- Six patients have gallectomy which increase the risk of liver disease.

\section{Recommendations}

1- Patient's knowledge should be increased by new educational and planning strategies through TV, radio, internet, newspapers to prevent risk factors like (heavy alcohol drinking, poly pharmacy).

2- The numbers of physicians specialized in liver disease are very low in our locality which required to increase these specialists in the future because liver diseases are in increasing in our locality.

3- According to our study results, the numbers of patients with hepatitis B virus are high; therefore, care need to be taken to prevent the transmission of this hepatitis B virus to healthy people where the test for hepatitis B virus should be done before marriage to prevent transmission through intercourse.

\section{REFERENCES}

Williams R. Global challenges in liver disease. Hepatology 2006; 44: 521-526.

Younossi ZM, Kanwa IF, Saab S, et al. The impact of hepatitis $\mathrm{C}$ burden: an evidence-

basedapproach.AlimentPharmacolTher20 14:39:518-31.

Center for Disease Control and Prevention. World Hepatitis Day, July 28; 2011. Available from URL: http://www.cdc.gov/Features/dsHepatitis Awareness/[cited22.11.11].

Louie KL, Forssen UM, Mundy LM, Pimenta JM. The high comorbidity burden of the hepatitis C virus infected population in the United States. BMC Infect Dis 2012; 12:86.

Chang PE, Wong GW, $\mathrm{Li} \mathrm{JW}$, et al. Epidemiology and clinical evolution of 
liver cirrhosis in Singapore. Ann. Acad. Med. Singapore, 2015; 44: 218-225.

http://www.healthline.com/human-bodymaps/liver.

A textbook of modern toxicology / Ernest Hodgson.-3rd ed. p. cm.l Includes bibliographical references and index. ISBN 0-471-26508-X 1.Toxicology. I. Title.

(Oxford Textbook of Medicine 4th edition (March 2003): by David A. Warrell (Editor), Timothy M. Cox (Editor), John D. Firth (Editor), Edward J., J R., M.D. Benz(Editor) By Oxford Press;).

Textbook of modern toxicology / Ernest Hodgson.-3rd ed. p. cm.l Includes bibliographical references and index. ISBN 0-471-26508-X 1.Toxicology. I. Title. RA1211.H62 2004/ 615.9—dc22.

http://www.liverfoundation.org/abouttheli ver/info/livercancer/.

Shasha Khairullah and Sanjiv Mahadeva / Translation, adaptation and validation of two versions of the Chronic Liver Disease Questionnaire in Malaysian patients for speakers of both English and Malay languages: a cross-sectional study/ https://www.ncbi.nlm.nih.gov/pmc/article s/PMC5777466/

Chevaliez S, Bouvier-Alias M, Laperche S, Pawlotsky JM.Performance of the Cobas AmpliPrep/Cobas TaqManreal-time PCR assay for hepatitis $\mathrm{B}$ virus DNA quantification. JClin Microbiol. 2008; 46:1716-23.

Marilena Durazzo, Paola Belci, Alessandro Collo, Vanessa Prandi, Erika Pistone, Maria Martorana, Roberto Gambino, and Simona Bo/Gender specific medicine in liver diseases: A point of view

Nathalie T. Burkert, Wolfgang Freidl, Johanna Muckenhuber, Willibald J. Stronegger, Éva Rásky / Self-perceived health, quality of life, and health-related behavior in obesity: is social status a mediator?

https://link.springer.com/article/10.1007/s 00508-012-0160-y

1- G. MARRONE1, F.G. VACCARO1, M. BIOLATO1, L. MIELE1, A. LIGUORI1, C. ARANEO1, F.R. PONZIANI1, N. MORES2, A. GASBARRINI1, A. GRIECO1/Drug-induced liver injury 2017: the diagnosis is not easy but always to keep in mind/https://www.europeanreview.org/w p/wp-content/uploads/122-134-DILI2017.pdf

Paul Y. Kwo, MD, FACG, FAASLD 1 , Stanley M. Cohen , MD, FACG, FAASLD 2 and Joseph K. Lim , MD, FACG, FAASLD/ ACG Practice Guideline: Evaluation of Abnormal Liver Chemistries/ http://acgblog.org/wpcontent/uploads/2016/12/AJG-Kwo-et-alACG-Liver-Chemistries-Guideline2017.pdf 